\title{
Antioxidants Improve the Viability of Stored Adult Retinal Pigment Epithelial-19 Cultures
}

\author{
Lara Pasovic · Jon R. Eidet • Torstein Lyberg • \\ Edward B. Messelt $\cdot$ Peder Aabel $\cdot$ Tor P. Utheim
}

To view enhanced content go to www.ophthalmology-open.com

Received: November 5, 2013 / Published online: March 29, 2014

(c) The Author(s) 2014. This article is published with open access at Springerlink.com

\section{ABSTRACT}

Introduction: There is increasing evidence that retinal pigment epithelium (RPE) can be used to treat age-related macular degeneration, one of the leading causes of blindness worldwide. However, the best way to store RPE to enable worldwide distribution is unknown. We investigated the effects of supplementing our previously published storage method with seven additives, attempting to improve the number of viable adult retinal pigment epithelial (ARPE)-19 cells after storage.

Electronic supplementary material The online version of this article (doi:10.1007/s40123-014-0024-9) contains supplementary material, which is available to authorized users.

L. Pasovic $(\bowtie) \cdot J$. R. Eidet · T. Lyberg · T. P. Utheim Department of Medical Biochemistry, Oslo University Hospital, Oslo, Norway

e-mail: larapasovic@gmail.com

E. B. Messelt

Department of Oral Biology,

University of Oslo, Oslo, Norway

P. Aabel

Division of Surgery, Ear, Nose and Throat

Department, Akershus University Hospital,

Lørenskog, Norway
Materials and methods: ARPE-19 cells were cultured on multiwell plates before being stored for 1 week at $16^{\circ} \mathrm{C}$. Unsupplemented Minimal Essential Medium (MEM) (control) and a total of seven individual additives (DADLE ([D-Ala ${ }^{2}, \quad$ D-Leu $\left.{ }^{5}\right]$-encephalin), capsazepine, docosahexaenoic acid (DHA), resveratrol, quercetin, simvastatin and sulforaphane) at three to four concentrations in MEM were tested. The individual effect of each additive on cell viability was analyzed with a microplate fluorometer. Cell phenotype was investigated by both microplate fluorometer and epifluorescence microscopy, and morphology by scanning electron microscopy.

Results: Supplementation of the storage medium with DADLE, capsazepine, DHA or resveratrol significantly increased the number of viable cells by $86.1 \% \pm 41.9 \%, 67.9 \% \pm$ $24.7 \%, \quad 36.5 \% \pm 10.3 \%$ and $21.1 \% \pm 6.4 \%$, respectively, compared to cells stored in unsupplemented MEM. DHA and resveratrol significantly reduced caspase-3 expression, while expression of RPE65 was maintained across groups.

Conclusion: The number of viable ARPE-19 cells can be increased by the addition of 
DADLE, capsazepine, DHA or resveratrol to the storage medium without perturbing apoptosis or differentiation.

Keywords: Additives; Age-related macular degeneration; Ophthalmology; Retinal pigment epithelium; Storage; Viability

\section{INTRODUCTION}

Age-related macular degeneration (AMD) is one of the world's leading causes of blindness and impairment or loss of the retinal pigment epithelium (RPE) is a central pathogenic factor [1]. The culture and implantation of RPE transplants is a promising avenue for treatment of AMD, and several studies have shown the capability of this approach to improve visual function [2-11]. Despite steadily improving strategies for cell replacement, tissue engineering of cell sheets that fulfill the requirements for transplantation is complex [12]. This is likely to lead to the centralization of the technology to highly specialized units. For further advancement of RPE replacement therapies, the establishment of a storage technique would give several advantages. First, a storage method allows for the transportation of the transplants from centralized units to eye clinics worldwide. Second, it may provide sufficient time to permit quality control of the cultured cells prior to transplantation. Third, storage allows microbiological assessment of the tissue before surgery [13]. Finally, it gives increased flexibility for both the patient and the surgeon in scheduling operations [14, 15]. With recent advances of RPE tissue engineering approaches, the need for improved storage and transportation methods for cultured RPE is anticipated to increase in coming years.

In a previous study by the authors, following an investigation of the effects of nine storage temperatures spanning between 4 and $37{ }^{\circ} \mathrm{C}$ for 1 week of storage, only $49 \%$ of viable cells were maintained at the best temperature $\left(16^{\circ} \mathrm{C}\right)$ [16]. The medium used was simple, containing only 4-(2-hydroxyethyl)-1-piperazineethanesulfonic acid (HEPES) and sodium bicarbonate-buffered Minimum Essential Medium (MEM) and gentamycin.

In the present study, the authors investigate whether the number of viable cells can be increased following 1 week of storage at $16^{\circ} \mathrm{C}$ by individually supplementing a basal storage medium with seven different substances; two of which are analgesics and five of which have antioxidant effects.

\section{MATERIALS AND METHODS}

\section{Cell Culture Media and Reagents}

Adult retinal pigment epithelial cells (ARPE-19) were purchased from the American Type Culture Collection (ATCC) (Manassas, VA, USA). $\quad$ Nunclon $^{\circledR} \quad \Delta$-surface multidishes (Thermo Scientific; Waltham, MA, USA), glass coverslips, syringes and pipettes were purchased from VWR International (West Chester, PA, USA). The calcein-acetoxymethyl ester (CAM) and the Minimum Essential Medium (MEM) were obtained from Invitrogen (Carlsbad, CA, USA). Dulbecco's Modified Eagle's Medium (DMEM): Nutrient Mixture F12, trypsinethylendiaminetetraacetic acid (EDTA), fetal bovine serum (FBS), penicillin, streptomycin, gentamycin, phosphate-buffered saline (PBS), HEPES, bovine serum albumin (BSA), sodium bicarbonate, propidium iodide (PI) solution, Triton X-100 solution and 4',6-diamidino-2phenylindole (DAPI) were all from SigmaAldrich (St. Louis, MO, USA). The rabbit anticleaved caspase-3 (Asp 175) antibody was supplied by Cell Signaling Technology 
(Danvers, MA, USA), while the mouse antiRPE65 antibody and the secondary antibodies; fluorescein isothiocyanate (FITC)-conjugated goat anti-mouse IgG and cyanine dye 3 (Cy3)conjugated goat anti-rabbit IgG were purchased from Abcam (Cambridge, UK). The additives [D$\mathrm{Ala}^{2}, \mathrm{D}-\mathrm{Leu}^{5}$ ]-encephalin (DADLE), capsazepine, docosahexaenoic acid (DHA), resveratrol, sulforaphane, simvastatin and quercetin were all provided by Sigma-Aldrich. Acrodisc syringe filters for sterile filtration were purchased from Pall Corporation (Port Washington, New York, USA).

This article does not contain any studies with human or animal subjects performed by any of the authors.

\section{Culture and Storage of Retinal Pigment Epithelial (RPE) Cells}

ARPE-19 cells were cultured in 95\% air and 5\% $\mathrm{CO}_{2}$ at $37^{\circ} \mathrm{C}$ in DMEM/F12 medium with $10 \%$ FBS, 50 units $/ \mathrm{mL}$ penicillin and $50 \mu \mathrm{g} / \mathrm{mL}$ streptomycin added. The cells were seeded on either Nunclon $\Delta$-surface 48 -well plates or on glass coverslips. After 2 days, the culture medium was changed. On day three, the culture medium was removed, and the cultures were rinsed with PBS before adding the storage medium. The unsupplemented storage medium consisted of 1.0 mL MEM, $25 \mathrm{mM}$ HEPES, $22.3 \mathrm{mM}$ sodium bicarbonate and $50 \mu \mathrm{g} / \mathrm{mL}$ gentamycin (hereafter named MEM). Storage media were individually supplemented with the additives, each at three or four concentrations, resulting in 26 experimental groups ( $n=12$ for DADLE, resveratrol, simvastatin and quercetin; $n=20$ for capsazepine; $n=8$ for DHA; $n=16$ for sulforaphane). The medium was sterile filtered (pore size $0.2 \mu \mathrm{m}$ ) before it was added to the wells. The control group comprised epithelial cells stored in unsupplemented MEM ( $n$ equal to that of each additive group). All the cultures were stored at $16{ }^{\circ} \mathrm{C}$ for 7 days, without change or addition of storage medium. The storage containers were custom built as previously reported [16].

\section{Viability Analysis}

Cell viability was analyzed after 1 week of storage by incubating the stored cells with PBS containing $1.0 \mu \mathrm{M}$ CAM for $1 \mathrm{~h}$. CAM fluorescence quantification was performed with a microplate fluorometer (Fluoroskan Ascent ${ }^{\mathrm{TM}}$, Thermo Scientific, Waltham, MA, USA) with the excitation/emission filter pair $485 \mathrm{~nm} / 538 \mathrm{~nm}$. Mean fluorescence was calculated for all additive groups. The reliability of the CAM measurements in determining cell number was demonstrated in a previous study [16].

\section{Phenotype Analysis}

\section{Preparations for the Phenotype Analysis}

Cell phenotype of stored cultures was determined by two methods: (1) microplate fluorometer (Fluoroskan Ascent) and (2) epifluorescence microscopy (Nikon Eclipse; Nikon Instruments, Tokyo, Japan). Twenty-four well multidishes with three-day cultured ARPE-19 cells stored for 7 days at $16{ }^{\circ} \mathrm{C}$ in MEM with additives were fixed in methanol for $15 \mathrm{~min}$ at room temperature. Cultures stored in unsupplemented MEM served as controls. To quantify cell number after storage by the microplate fluorometer, methanol-fixed cells were incubated with PI diluted in PBS (1:200) for $3 \mathrm{~min}$ before the fluorescence was measured with a $530 \mathrm{~nm} / 620 \mathrm{~nm}$ excitation/emission filter. Thereafter, permeabilizing/blocking solution containing PBS with $1 \%$ BSA and $0.2 \%$ Triton $\mathrm{X}-100$ was added for a 30-min incubation.

Primary antibodies were diluted in PBS with $1 \%$ BSA to obtain a concentration of 1:400 and 1:200 for anti-caspase-3 and anti-RPE65, 
respectively. Fixed cells were incubated with primary antibodies at $4{ }^{\circ} \mathrm{C}$ overnight. For the negative control, primary antibodies were omitted. The goat anti-rabbit Cy3-conjugated secondary antibodies were diluted to $1: 10,000$ and the goat anti-mouse FITC-conjugated secondary antibodies were diluted to 1:250, both in PBS containing 1\% BSA. Cells were incubated with secondary antibodies for $1 \mathrm{~h}$ and rinsed with PBS before the addition of $1 \mu \mathrm{g} /$ $\mathrm{mL}$ DAPI to visualize cell nuclei using epifluorescence microscopy.

\section{Fluorescence Quantification using the Microplate Fluorometer}

After incubation with FITC-conjugated secondary antibodies as described above, samples were analyzed with a microplate fluorometer (Fluoroskan Ascent; excitation/ emission filters of $485 \mathrm{~nm} / 538 \mathrm{~nm})$. PI fluorescence intensity was measured to quantify the number of cells in each well, as the number of methanol-fixed cells was highly correlated with PI fluorescence intensity $\left(R^{2}=0.996 ; P<0.001\right.$; data not shown). FITC fluorescence intensity per cell was obtained by the following calculation: FITC fluorescence intensity per well/PI fluorescence intensities per well. Mean fluorescence was calculated for all groups.

\section{Fluorescence Quantification of Epifluorescence} Microscopy Photomicrographs using ImageJ

Using a Nikon Eclipse $\mathrm{Ti}$ fluorescence microscope (Nikon Instruments, Tokyo, Japan) with a motorized microscope stage, photomicrographs were captured at five predetermined locations in each well. Photomicrographs were captured at $200 \times$ magnification with a Nikon DS-Qi1 black-andwhite camera (Nikon Instruments). Identical exposure length and gain were used for all compared groups, while keeping the image brightness within the camera's dynamic range. Image J software (version 1.44) [17] was used to convert the corresponding FITC/Cy3 and DAPI photomicrographs to 8-bit gray scale pictures, and was also used to make selections of preset diameters surrounding cell nuclei in the DAPI photomicrographs. These selections were transferred to the caspase-3 and RPE65 photomicrographs, and fluorescence intensities were measured within these selections only (Fig. 1). This allowed for the normalization of fluorescence intensity according to cell number in each well. Background fluorescence intensity measured in controls without primary antibody was subtracted from all samples. The mean fluorescence value in each well was an average of the five predetermined positions.

\section{Morphology Analysis}

ARPE-19 cells were cultured until confluence on glass coverslips. Cell cultures were then stored at $16^{\circ} \mathrm{C}$ for 7 days in MEM supplemented with selected additives. Cells stored without additives in the storage medium and cells that had not been stored served as controls. Stored cultures were prepared for scanning electron microscopy (SEM) by fixation in $2.5 \%$ glutaraldehyde solution, dehydration in increasing concentrations of ethanol and drying with the critical point method (Polaron E3100 Critical Point Drier; Polaron Equipment Ltd, Watford, UK). Platinum-coated samples were photographed with an XL30 ESEM electron microscope (Philips, Amsterdam, The Netherlands).

\section{Statistical Analysis}

Statistical analysis was performed using one-way ANOVA with Tukey's post hoc comparisons [SPSS 


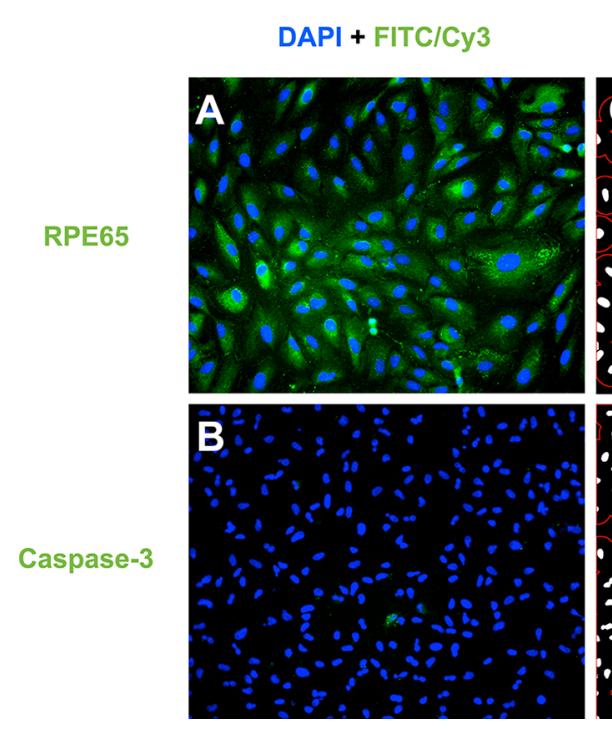

Fig. 1 Photomicrographs showing the expression of RPE65 (a, e) and caspase-3 (b, f) in cultured ARPE-19 cells. Selections (red) around all cell nuclei (white) (c, d) were automatically created by ImageJ software. RPE65 (e) and caspase-3 (f) fluorescence intensity was then measured solely within the red selections, thereby

ver. 19.0 (IBM, New York, USA)]. $P$ values below 0.05 were considered significant. Data were expressed as mean \pm standard error of the mean.

\section{RESULTS}

\section{Viability of Stored ARPE-19 Cell Cultures}

Cell survival following 1 week of storage in all 26 experimental groups was assessed by CAM fluorescence. Of the seven additives tested, supplementation of the storage medium with $1 \mathrm{mM}$ DADLE, $1 \mu \mathrm{M}$ capsazepine, $50 \mathrm{nM}$ DHA or $30 \mu \mathrm{M}$ resveratrol significantly increased the number of viable cells by $86.1 \% \pm 41.9 \%$, $67.9 \% \pm 24.7 \%, \quad 36.5 \% \pm 10.3 \% \quad$ and $21.1 \% \pm 6.4 \%$, respectively, compared to cells stored in unsupplemented MEM (Fig. 2a-d). These four additives also demonstrated a concentration-dependent effect on CAM fluorescence. The addition of quercetin, normalizing for the number of cells in each image. Magnification $\times 200$. ARPE-19 adult retinal pigment epithelium 19, Cy3 cyanine dye 3, DAPI 4', 6-diamidino-2-phenylindole, FITC fluorescein isothiocyanate, $R P E 65$ retinal pigment epithelium-specific protein $65 \mathrm{kDa}$

simvastatin or sulforaphane to the storage medium did not increase cellular CAM fluorescence after storage (Fig. 2e, f).

\section{Phenotype of Stored ARPE-19 Cell Cultures}

As DADLE, capsazepine, DHA and resveratrol added to MEM increased the number of live cells after storage, these substances were also analyzed for their effect on ARPE-19 phenotype after storage ( $n=8$ for each additive).

To assess the level of apoptosis, caspase- 3 expression was measured by ImageJ, revealing a significantly lower expression in cells stored in MEM with either DHA or resveratrol compared to cells stored in unsupplemented MEM (Fig. 3). The caspase-3 expression of cells stored in unsupplemented MEM was already low $(<0.1 \%$ caspase-3 positive cells of total cell number), as reported earlier [16]. Relative to this low 

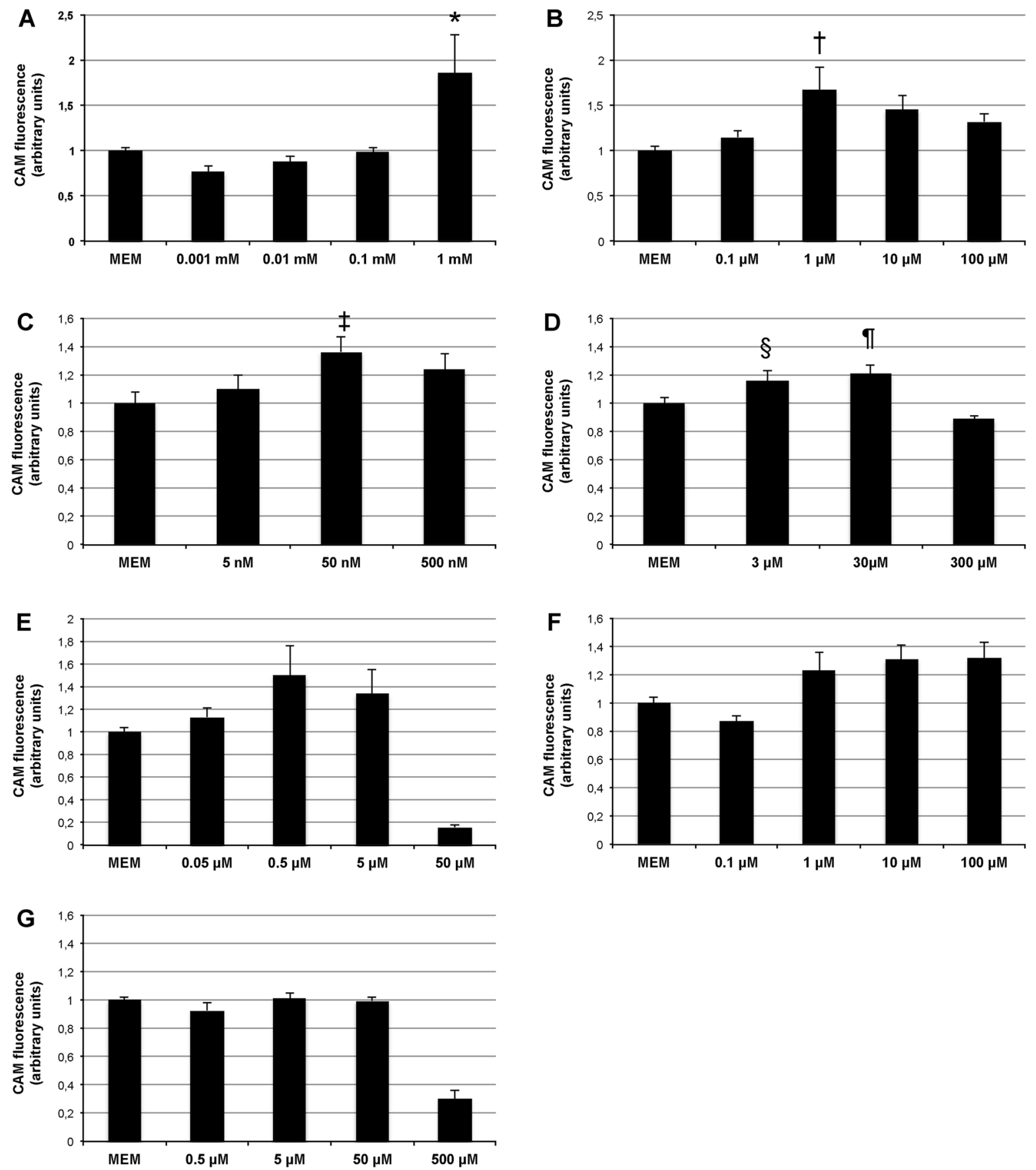

Fig. 2 Bar charts demonstrating viability of cultured ARPE-19 cells after storage at $16^{\circ} \mathrm{C}$ for 7 days. Viability was assessed with a calcein-acetoxymethyl ester (CAM) reagent by a microplate fluorometer. Compared to the unsupplemented storage group, MEM with the addition of DADLE (a), capsazepine (b), DHA (c) or resveratrol (d) demonstrated a concentration-dependent increase in viability. Addition of sulforaphane (e), simvastatin (f), or quercetin $(\mathbf{g})$ to the storage medium had no effect on cell

viability. ${ }^{*} P<0.05$ compared to MEM and $0.1 \mathrm{mM}$ DADLE; $P<0.01$ compared to $0.001 \mathrm{mM}$ DADLE and $0.01 \mathrm{mM}$ DADLE. ${ }^{\dagger} P<0.05$ compared to MEM. ${ }^{\ddagger} P<0.05$ compared to MEM. ${ }^{\S} P<0.01$ compared to $300 \mu \mathrm{M}$ resveratrol. ${ }^{\top} P<0.05$ compared to MEM; $P<0.01$ compared to $300 \mu \mathrm{M}$ resveratrol. Error bars standard error of the mean. CAM calcein-acetoxymethyl ester, DADLE [D-Ala ${ }^{2}$, D-Leu $\left.{ }^{5}\right]$-encephalin, $D H A$ docosahexaenoic acid, MEM minimal essential medium 


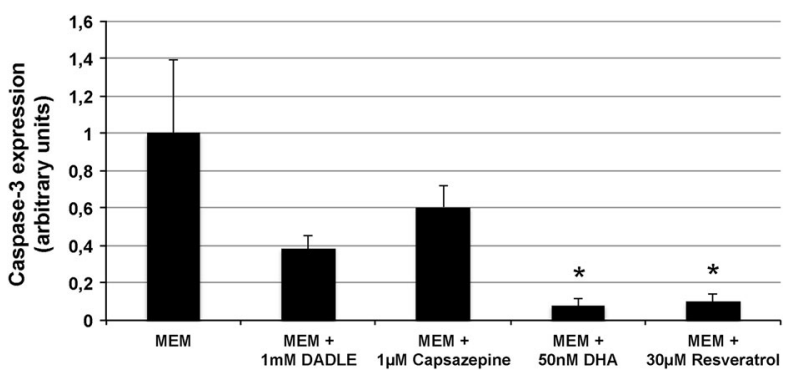

Fig. 3 ImageJ quantification of caspase-3 expression after storage. Bar chart demonstrating caspase-3 expression in cultured ARPE- 19 cells stored at $16^{\circ} \mathrm{C}$ for 7 days. The cells were stored in unsupplemented MEM (control) or MEM supplemented with DADLE $(1 \mathrm{mM})$, capsazepine $(1 \mu \mathrm{M})$, DHA $(50 \mathrm{nM})$ or resveratrol $(30 \mu \mathrm{M})$. Compared to the unsupplemented MEM group, caspase-3 expression was

percentage, cells stored with DHA or resveratrol showed a caspase- 3 expression of $8.0 \% \pm 4.0 \%$ and $9.8 \% \pm 4.6 \%$, respectively $(<0.01 \%$ caspase3 positive cells of total cell number).

To reveal whether the additives affect ARPE19 cell differentiation after storage, expression of the differentiation marker RPE65 was quantified by both ImageJ and a microplate fluorometer. None of the additives had any effect on RPE65 expression irrespective of the analysis used (Fig. 4).

\section{Morphology of Stored ARPE-19 Cell Cultures}

DADLE, capsazepine, DHA and resveratrol were assessed by SEM for their potential effects on cell morphology following storage. No obvious difference in morphology was revealed between the supplemented versus the unsupplemented groups (Fig. 5).

\section{DISCUSSION}

The present study shows that the number of viable cultured ARPE-19 cells following 1 week of storage can be increased by adding DADLE, significantly decreased for both DHA $(50 \mathrm{nM})$ and resveratrol $(30 \mu \mathrm{M})$ when assessed by ImageJ. ${ }^{*} P<0.01$ compared to MEM. Error bars standard error of the mean. $A R P E-19$ adult retinal pigment epithelium 19, DADLE $\left[\mathrm{D}-\mathrm{Ala}^{2}, \mathrm{D}-\mathrm{Leu}^{5}\right]$-encephalin, $D H A$ docosahexaenoic acid, $M E M$ minimal essential medium

capsazepine, DHA or resveratrol to a serum- and xenobiotic-free MEM-based storage medium. The other antioxidants, quercetin, simvastatin and sulforaphane, however, did not improve the viability results. Addition of DADLE, capsazepine, DHA or resveratrol to MEM did not change the level of differentiation. Addition of DHA or resveratrol significantly reduced the caspase-3 expression, corroborating the viability data. Cell morphology appeared unaffected after storage in all groups. Neither the control cultures nor the cultures that had been subjected to storage were fully confluent, a finding that is in line with the results from an earlier study from the authors [16]. Notably, the authors could not identify a marked increase in signs of cell apoptosis, such as cell membrane blebbing or condensation of the nucleus or cytosol, in the stored cultures.

It is critical to maintain the viability of the cultured retinal pigment epithelial cells during the storage period for the graft to function optimally upon transplantation into the subretinal space. However, in a previous study using the same culture protocol as described in the present study, the average number of viable cells reached only $49 \%$ in the most favorable 

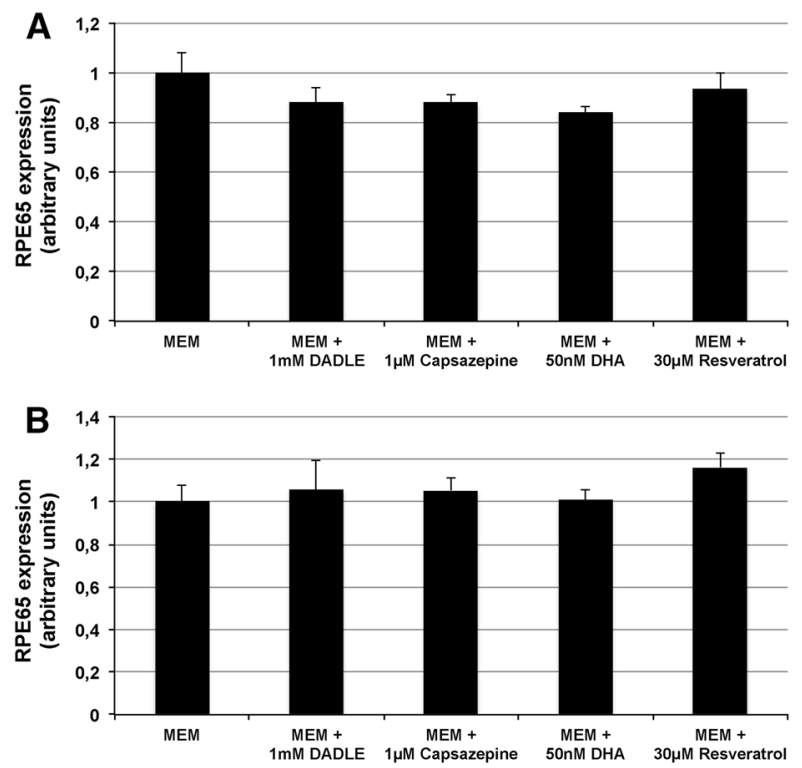

Fig. 4 a ImageJ quantification of RPE65 expression after storage. b Microplate fluorometer quantification of RPE65 expression after storage. Bar charts demonstrating RPE65 expression in cultured ARPE-19 cells stored at $16^{\circ} \mathrm{C}$ for 7 days. The cells were stored in unsupplemented MEM (control) or MEM supplemented with $1 \mathrm{mM}$ DADLE, $1 \mu \mathrm{M}$ capsazepine, $50 \mathrm{nM}$ DHA or $30 \mu \mathrm{M}$ resveratrol. Compared to the unsupplemented MEM group, the

temperature group $\left(16^{\circ} \mathrm{C}\right)$ compared to the unstored control [16].

As MEM consists of inorganic salts, amino acids, vitamins and glucose, the authors hypothesized that viability could be enhanced by supplementing this basal medium with certain additives that have proved favorable in other, but unrelated experiments [18-34]. The simple composition of the basal medium used in the experimental groups eases the interpretation of the individual effects of each added substance.

A storage temperature of $16^{\circ} \mathrm{C}$ could be sufficiently high to prevent most of the hypothermic-associated injurious factors, including reactive oxidant formation and disturbances in cellular ion homeostasis [35]. The authors hypothesized, however, that antioxidant protection using their storage additives did not change RPE65 expression when assessed by either ImageJ (a) or a microplate fluorometer (b). Error bars standard error of the mean. DADLE [D-Ala $\left.{ }^{2}, \mathrm{D}-\mathrm{Leu}^{5}\right]$ encephalin, $D H A$ docosahexaenoic acid, $M E M$ minimal essential medium, RPE65 retinal pigment epitheliumspecific protein $65 \mathrm{kDa}$

protocol could be advantageous. Both increased production of oxidizing species or a decrease in the effectiveness of the antioxidant defense mechanisms can result in oxidative stress [36]. The effects of oxidative stress, however, are dependent on the magnitude of these changes. The cell may be able to overcome small perturbations and regain its original state. Conversely, more severe oxidative stress may trigger apoptosis, whereas substantial oxidative stress may cause necrosis [37]. Production of reactive oxygen species, such as free radicals and peroxidases, is considered a potentially devastating feature of oxidative stress [38].

By adding $1 \mathrm{mM}$ DADLE to the storage medium, the number of viable cells increased by $86.1 \%$ after storage. DADLE is an analogue of endogenous $\delta$ opioid encephalin, which has been shown to induce hibernation, enhance 


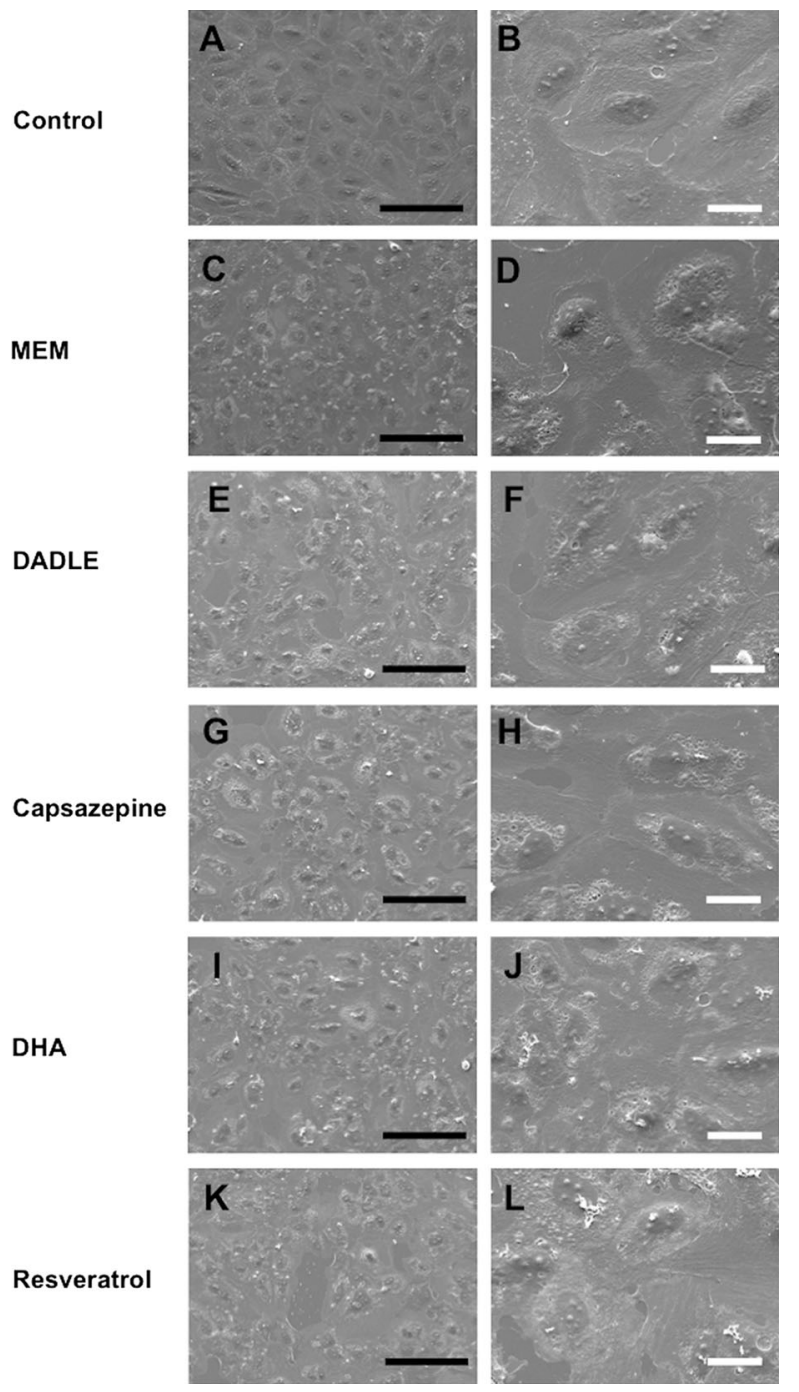

Fig. 5 Scanning electron photomicrographs of ARPE-19 cultures. Scanning electron photomicrographs showing cultured ARPE-19 cells without subsequent storage (a, b) and after storage for 7 days at $16^{\circ} \mathrm{C}$ in unsupplemented MEM (c, d), and MEM supplemented with $1 \mathrm{mM}$ $\operatorname{DADLE}(\mathbf{e}, \mathbf{f}), 1 \mu \mathrm{M}$ capsazepine $(\mathbf{g}, \mathbf{h}), 50 \mathrm{nM}$ DHA $(\mathbf{i}, \mathbf{j})$, or $30 \mu \mathrm{M}$ resveratrol $(\mathbf{k}, \mathbf{l})$. All storage groups displayed few signs of cell damage and appeared morphologically similar with respect to cell-cell and cell-substrate attachment. Images are representative of three independent samples. Scale bars $100 \mu \mathrm{m}$ (black); $20 \mu \mathrm{m}$ (white). ARPE19 adult retinal pigment epithelium 19,DADLE [D-Ala ${ }^{2}$, D-Leu ${ }^{5}$-encephalin, $D H A$ docosahexaenoic acid, $M E M$ minimal essential medium

survival of transplanted organs, and block or reverse neurodegeneration induced by methamphetamine [18, 19]. Its effects are comparable to those of the hibernation induction trigger (HIT), which initiates hibernation in mammals by lowering body temperature and reducing metabolism [19]. These features might be relevant in the effect of DADLE on stored RPE cell cultures.

A concentration of $1.0 \mu \mathrm{M}$ capsazepine in the storage medium increased cell viability by $67.9 \%$ compared to control cultures. Capsazepine is a specific antagonist of the transient receptor potential vanilloid (TRPV1) channel, a receptor that is a significant molecular transducer of painful stimuli related to temperature, mechanical stress and acidity, which lead to intracellular calcium changes [20, 21]. TRPV1, $-2,-3$ and -4 channels have been identified in both freshly isolated primary human RPE cells and ARPE-19 cells, with the same expression profile being observed for both cell types [39]. Activation of TRPV1 increases the release of interleukin (IL)- 6 and IL-8, and the ability of TRPV1 channels to regulate intracellular calcium $\left(\mathrm{Ca}^{2+}\right)$ can be almost completely blocked by capsazepine [21].

By adding $50 \mathrm{nM}$ DHA to the storage medium, the average amount of viable cells after storage increased by $36.5 \%$. DHA is highly prevalent in photoreceptor and synaptic membranes [40, 41], and is crucial for development of the retina and brain. RPE cells both recycle DHA from phagocytosed photoreceptor outer segments and take up DHA from the blood, before delivering it to the photoreceptors to counterbalance their continuous outer segment shedding [22, 41]. The addition of DHA to ARPE-19 cell cultures has an inhibitory effect on cellular oxidative stress [22, 41], specifically by upregulating antiapoptotic proteins and down-regulating proapoptotic proteins [23]. These effects might be reflected in the increase in cell viability and 
reduction of caspase-3 expression demonstrated in the current study.

By adding $30 \mu \mathrm{M}$ resveratrol to the storage medium, the average number of viable cells after storage increased by $21.1 \%$. Resveratrol is a natural phenol with antioxidant activity. It has been reported to prevent cell death and caspase activation in RPE cells in response to exposure to hydrogen peroxide $\left(\mathrm{H}_{2} \mathrm{O}_{2}\right)$ and toxic components found in cigarette smoke [24-27]. These antioxidant effects might have contributed to increasing cell viability in the current study.

Sulforaphane, simvastatin, and quercetin were also assessed, but these substances did not have any advantageous effects on the cells post storage. Sulforaphane is an isothiocyanate isolated from broccoli, which has powerful inductive effects on phase two detoxification enzymes (e.g., glutathione transferases) [28, 30]. Treatment of ARPE-19 cells with sulforaphane has been shown to reduce the toxic effect of oxidative stressors [28] and photooxidation [29]. Simvastatin has been reported to suppress oxidant-induced reactive oxygen species accumulation and apoptosis of RPE cells, and prevent oxidative stress-induced activation [31]. Furthermore, it protects neurons from cytotoxicity both in vivo and in vitro by upregulating B cell lymphoma 2 (Bcl-2) [32]. Quercetin, a flavonoid, is a dietary antioxidant that has been reported to have the potential to strengthen survival signals [33]. It is also a chelating agent, able to inactivate the metal iron responsible for the generation of reactive oxidative species, thereby protecting DNA from oxidative damage [34].

Thus, all seven additives explored in the current study were carefully chosen based on their known cell supportive effects. Prior to the study all were regarded as equally promising, making both the positive and negative results interesting. To the knowledge of the authors, there are no previous studies investigating the effect of these seven substances on storage of cultured RPE cells.

A possible limitation of the current study is the sole use of the ARPE-19 cell line as a model organism for RPE. The ARPE-19 cell line has been indispensable in RPE research over the last decades and is recognized for displaying significant functional differentiation [42, 43], even though the cell line does not mirror all the functions and characteristics of native RPE [44, 45]. Several studies have shown that native RPE exhibits considerable regional variation, and that culture models of the RPE thus are inherently heterogeneous [46-48]. RPE cells in culture, including primary cells and ARPE-19 cells, can display a heterogeneity that exceeds the normal variation described in RPE in vivo $[44,49-51]$. Due to the inherent heterogeneity of RPE cells, future studies based on additional RPE sources would be advantageous. In addition, further studies are warranted to confirm the results of this study under various storage conditions and to elucidate the mechanisms by which DADLE, capsazepine, DHA and resveratrol exert their effects on stored ARPE-19 cells.

\section{CONCLUSION}

In conclusion, this study demonstrates that the number of viable ARPE-19 cells can be increased by the addition of DADLE, capsazepine, DHA or resveratrol to the storage medium. Furthermore, addition of DHA or resveratrol to the storage medium can reduce caspase-3 expression of ARPE-19 cells. All four substances maintained RPE65 expression, and no obvious changes in cell morphology occurred. 


\section{ACKNOWLEDGMENTS}

The study has received funding from the Norwegian Research Council and the SouthEastern Norway Regional Health Authority.

All named authors meet the ICMJE criteria for authorship for this manuscript, take responsibility for the integrity of the work as a whole, and have given final approval for the version to be published.

The authors wish to thank Steinar Stølen at the Department of Oral Biology, Faculty of Dentistry, the University of Oslo, for excellent assistance with scanning electron microscopy, and Catherine Jackson at the Department of Medical Biochemistry, Oslo University Hospital, for proofreading the manuscript.

Conflict of interest. L Pasovic has filed a patent application for a novel RPE storage medium based on the results described in this manuscript.

JR Eidet has filed a patent application for a novel RPE storage medium based on the results described in this manuscript.

TP Utheim has filed a patent application for a novel RPE storage medium based on the results described in this manuscript.

T Lyberg, EB Messelt and P Aabel declare no conflicts of interest.

Compliance with ethics. This article does not contain any studies with human or animal subjects performed by any of the authors.

Open Access. This article is distributed under the terms of the Creative Commons Attribution Noncommercial License which permits any noncommercial use, distribution, and reproduction in any medium, provided the original author(s) and the source are credited.

\section{REFERENCES}

1. Jager RD, Mieler WF, Miller JW. Age-related macular degeneration. N Engl J Med. 2008;358:2606-17.

2. da Cruz L, Chen FK, Ahmado A, Greenwood J, Coffey P. RPE transplantation and its role in retinal disease. Prog Retina Eye Res. 2007;26:598-635.

3. Lund RD, Adamson P, Sauve Y, et al. Subretinal transplantation of genetically modified human cell lines attenuates loss of visual function in dystrophic rats. Proc Natl Acad Sci USA. 2001;98:9942-7.

4. McGill TJ, Lund RD, Douglas RM, Wang S, Lu B, Prusky GT. Preservation of vision following cellbased therapies in a model of retinal degenerative disease. Vision Res. 2004;44:2559-66.

5. Sheridan CM, Mason S, Pattwell DM, Kent D, Grierson I, Williams R. Replacement of the RPE monolayer. Eye. 2009;23:1910-5.

6. Yaji N, Yamato M, Yang J, Okano T, Hori S. Transplantation of tissue-engineered retinal pigment epithelial cell sheets in a rabbit model. Biomaterials. 2009;30:797-803.

7. Falkner-Radler CI, Krebs I, Glittenberg C, et al. Human retinal pigment epithelium (RPE) transplantation: outcome after autologous RPE-choroid sheet and RPE cell-suspension in a randomised clinical study. $\mathrm{Br} \mathrm{J}$ Ophthalmol. 2011;95:370-5.

8. Coffey PJ, Girman S, Wang SM, et al. Long-term preservation of cortically dependent visual function in RCS rats by transplantation. Nat Neurosci. 2002;5:53-6.

9. Wang S, Lu B, Wood P, Lund RD. Grafting of ARPE19 and Schwann cells to the subretinal space in RCS rats. Invest Ophthalmol Vis Sci. 2005;46:2552-60.

10. Zhang T, Hu Y, Li Y, et al. Photoreceptors repair by autologous transplantation of retinal pigment epithelium and partial-thickness choroid graft in rabbits. Invest Ophthalmol Vis Sci. 2009;50:2982-8.

11. Sauve Y, Pinilla I, Lund RD. Partial preservation of rod and cone ERG function following subretinal injection of ARPE-19 cells in RCS rats. Vision Res. 2006;46:1459-72.

12. Ahmad S, Osei-Bempong C, Dana R, Jurkunas U. The culture and transplantation of human limbal stem cells. J Cell Physiol. 2010;225:15-9.

13. Utheim TP, Raeder $\mathrm{S}$, Utheim OA, de la Paz M, Roald B, Lyberg T. Sterility control and long-term 
eye-bank storage of cultured human limbal epithelial cells for transplantation. $\mathrm{Br} J$ Ophthalmol. 2009;93:980-3.

14. Utheim TP. Limbal epithelial cell therapy: past, present, and future. Methods Mol Biol. 2013;1014:3-43.

15. Utheim TP, Lyberg $\mathrm{T}$, Raeder $\mathrm{S}$. The culture of limbal epithelial cells. Methods Mol Biol. 2013;1014:103-29.

16. Pasovic L, Utheim TP, Maria R, et al. Optimization of storage temperature for cultured ARPE-19 cells. J Ophthalmol. 2013;2013:1-11.

17. ImageJ Software. http://rsbweb.nih.gov/ij/. Last Accessed March 9, 2014.

18. Tsao L-I, Su T-P. Hibernation-induction peptide and cell death: [D-Ala2, D-Leu5] enkephalin blocks Baxrelated apoptotic processes. Eur J Pharmacol. 2001;428(1):149-51.

19. Vecchio L, Soldani C, Bottone MG, et al. DADLE induces a reversible hibernation-like state in HeLa cells. Histochem Cell Biol. 2006;125:193-201.

20. Radtke C, Sinis N, Sauter M, et al. TRPV channel expression in human skin and possible role in thermally induced cell death. J Burn Care Res. 2011;32:150-9.

21. Mergler S, Valtink M, Coulson-Thomas VJ, et al. TRPV channels mediate temperature-sensing in human corneal endothelial cells. Exp Eye Res. 2010;90:758-70.

22. Mukherjee PK, Marcheselli VL, Serhan CN, Bazan NG. Neuroprotectin D1: a docosahexaenoic acidderived docosatriene protects human retinal pigment epithelial cells from oxidative stress. Proc Natl Acad Sci USA. 2004;101:8491-6.

23. Antony R, Lukiw WJ, Bazan NG. Neuroprotectin D1 induces dephosphorylation of Bcl-xL in a PP2Adependent manner during oxidative stress and promotes retinal pigment epithelial cell survival. J Biol Chem. 2010;285:8.

24. Mansoor S, Gupta N, Patil AJ, et al. Inhibition of apoptosis in human retinal pigment epithelial cells treated with benzo(e)pyrene, a toxic component of cigarette smoke. Invest Ophthalmol Vis Sci. 2010;51:2601-7.

25. King RE, Kent KD, Bomser JA. Resveratrol reduces oxidation and proliferation of human retinal pigment epithelial cells via extracellular signalregulated kinase inhibition. Chem Biol Interact. 2005;151:143-9.
26. Pintea A, Rugina D, Pop R, Bunea A, Socaciu C, Diehl HA. Antioxidant effect of trans-resveratrol in cultured human retinal pigment epithelial cells. J Ocular Pharmacol Ther. 2011;27:315-21.

27. Sheu SJ, Liu NC, Chen JL. Resveratrol protects human retinal pigment epithelial cells from acrolein-induced damage. J Ocular Pharmacol Ther. 2010;26(3):231-6.

28. Gao X, Dinkova-Kostova AT, Talalay P. Powerful and prolonged protection of human retinal pigment epithelial cells, keratinocytes, and mouse leukemia cells against oxidative damage: the indirect antioxidant effects of sulforaphane. Proc Natl Acad Sci USA. 2001;98:15221-6.

29. Gao X, Talalay P. Induction of phase 2 genes by sulforaphane protects retinal pigment epithelial cells against photooxidative damage. Proc Natl Acad Sci USA. 2004;101:10446-51.

30. Hanneken A, Lin FF, Johnson J, Maher P. Flavonoids protect human retinal pigment epithelial cells from oxidative-stress-induced death. Invest Ophthalmol Vis Sci. 2006; 47:3164-77.

31. Qian J, Keyes KT, Long B, Chen G, Ye Y. Impact of HMG-CoA reductase inhibition on oxidant-induced injury in human retinal pigment epithelium cells. J Cell Biochem. 2011;112:10.

32. Johnson-Anuna LN, Eckert GP, Franke C, Igbavboa U, Muller WE, Wood WG. Simvastatin protects neurons from cytotoxicity by up-regulating Bcl-2 mRNA and protein. J Neurochem. 2007;101:77-86.

33. Dajas F. Life or death: neuroprotective and anticancer effects of quercetin. J Ethnopharmacol. 2012;143:383-96.

34. Kook D, Wolf AH, Yu AL, et al. The protective effect of quercetin against oxidative stress in the human RPE in vitro. Invest Ophthalmol Vis Sci. 2008;49:1712-20.

35. Rauen U, de Groot $H$. Mammalian cell injury induced by hypothermia-the emerging role for reactive oxygen species. Biol Chem. 2002;383:477-88.

36. Schafer FQ, Buettner GR. Redox environment of the cell as viewed through the redox state of the glutathione disulfide/glutathione couple. Free Radic Biol Med. 2001;30:1191-212.

37. Lennon SV, Martin SJ, Cotter TG. Dose-dependent induction of apoptosis in human tumour cell lines by widely diverging stimuli. Cell Prolif. 1991;24:203-14. 
38. Valko M, Morris H, Cronin MT. Metals, toxicity and oxidative stress. Curr Med Chem. 2005;12:1161-208.

39. Cordeiro S, Seyler S, Stindl J, Milenkovic VM, Strauss O. Heat-sensitive TRPV channels in retinal pigment epithelial cells: regulation of VEGF-A secretion. Invest Ophthalmol Vis Sci. 2010;51:6001-8.

40. Donoso LA, Edwards AO, Frost A, et al. Autosomal dominant Stargardt-like macular dystrophy. Surv Ophthalmol. 2001;46:149-63.

41. Sparrow JR, Hicks D, Hamel CP. The retinal pigment epithelium in health and disease. Curr Mol Med. 2010;10:802-23.

42. Dunn KC, Aotaki-Keen AE, Putkey FR, Hjelmeland LM. ARPE-19, a human retinal pigment epithelial cell line with differentiated properties. Exp Eye Res. 1995;62:155-69.

43. Dunn KC, Marmorstein AD, Bonilha VL, RodriguezBoulan E, Giordano F, Hjelmeland LM. Use of the ARPE-19 cell line as a model of RPE polarity. Invest Ophthalmol Vis Sci. 1998;39:6.

44. Luo Y, Zhuo Y, Fukuhara M, Rizzolo LJ. Effects of culture conditions on heterogeneity and the apical junctional complex of the ARPE-19 cell line. Invest Ophthalmol Vis Sci. 2006;47:3644-55.

45. Tian J, Ishibashi K, Honda S, Boylan SA, Hjelmeland LM, Handa JT. The expression of native and cultured human retinal pigment epithelial cells grown in different culture conditions. $\mathrm{Br} J$ Ophthalmol. 2005;89:1510-7.

46. Burke JM, Cao F, Irving PE. High levels of E-/Pcadherin: correlation with decreased apical polarity of $\mathrm{Na} / \mathrm{K}$ ATPase in bovine RPE cells in situ. Invest Ophthalmol Vis Sci. 2000;41:1945-52.

47. Burke JM, Hjelmeland LM. Mosaicism of the retinal pigment epithelium: seeing the small picture. Mol Interv. 2005;5:241-9.

48. Burke JM, Cao F, Irving PE, Skumatz CMB. Expression of E-cadherin by human retinal pigment epithelium: delayed expression in vitro. Invest Ophthalmol Vis Sci. 1999;40:2963-70.

49. Ando A, Ueda M, Uyama M, Masu Y, Okumura T, Ito $\mathrm{S}$. Heterogeneity in ornithine cytotoxicity of bovine retinal pigment epithelial cells in primary culture. Exp Eye Res. 2000;70:89-96.

50. McKay BS, Burke JM. Separation of phenotypically distinct subpopulations of cultured human retinal pigment epithelial cells. Exp Cell Res. 1994;213:85-92.

51. Albert DM, Tso MOM, Rabson AS. In vitro growth of pure cultures of retinal pigment epithelium. Arch Ophthal. 1972;88:63-9. 